\title{
Improving Negotiation Outcomes Between American And Chinese Partners: A Framework For Practice
}

Rashmi Prasad, PhD, University of Alaska Anchorage, USA Yong Cao, PhD, University of Alaska Anchorage, USA

\begin{abstract}
Cross-cultural negotiations between the United States and China at government level, business level as well as individual level are important for both countries. However, current empirical findings about the cross-cultural negotiations outcomes indicate that they tend to be inferior to those obtained in intra-cultural negotiations due to various barriers, which include differences of language, ethical systems, and a range of cultural traits from risk-propensity to individualism. For Americans bargaining with persons from collectivist cultures such as China can be especially difficult, compounded by group dynamics such as in-group favoritism, inter-group attributions, as well as, histories of conflict and suspicion of foreigners. Attaining to effective positive-sum bargaining requires, among other factors, a perception of one's counterpart as ethical, a predictable process of information disclosure and the building of trust. These are especially important in cross-cultural negotiations involving Chinese partners. In this paper we review the barriers to effective cross-cultural bargaining between Americans and Chinese partners and provide a framework for improved outcomes, with a special focus on factors such as group dynamics, information disclosure and Confucian ethical framing. The framework could be useful tool for improving bargaining practices between government officials and business managers between the countries.
\end{abstract}

Keywords: China; United States; Cross-cultural; Negotiation; Conflict Management; Bargaining; Collectivism; Individualism

\section{INTRODUCTION}

mproved negotiation outcomes between U.S. and Chinese partners are a critically important matter for government, business and other organizations. Currently, the international economic system largely pivots on the U.S.-China trading and financial relationship. Bilateral trade volume between these two countries is the largest in the world and U.S. interest rates largely reflect this fact. The world economy is unlikely to recover and prosper without much better coordination between the two countries, which can only be produced through effective negotiations among a large number of private and public actors. While our expectations for cooperation and leadership from these two countries may be high, the literature on cross-cultural negotiations informs us that this will be a daunting task.

Research on cross-cultural negotiation indicates that cross-cultural negotiation outcomes tend to be inferior to intra-cultural negotiations (Brett and Okamura 1998; Graham 1993). The barriers to negotiating effectively across cultures are many, including language, ethical systems, and a range of cultural traits from individualism to risk propensity (Foster 1992). The barriers to effective positive-sum bargaining within cultures are also considerable. Effective positive-sum bargaining requires the building of trust, which is aided by both a mutual perception of ethical behavior in negotiation partners (Volkema et al. 2004) and a predictable process of information disclosure. The perception of ethical behavior in a negotiation partner who is also separated by a cultural barrier presents additional difficulties in reaching desirable negotiation outcomes. In this paper we examine the difficulties 
of U.S.-China inter-cultural negotiations and outline a framework for their improvement. We propose the utilization of Confucian ethical framing as a means of improving processes and outcomes in integrative bargaining, while being cognizant of the role of additional factors such as Cultural Intelligence (CQ), moral maturity and group dynamics.

\section{EMPIRICAL FINDINGS OF CROSS CULTURAL NEGOTIATION}

Numerous empirical studies have compared the outcomes for intra-cultural and inter-cultural negotiations. Results have varied with the country pairs that are selected (Lewicki et al. 2006), but a broad review indicates that intra-cultural negotiations tend to produce better outcomes than inter-cultural bargaining. This seems to be true of both integrative and distributive negotiation situations, though sufficient studies controlling for bargaining situation have not been conducted. In research that compares negotiation processes, rather than outcomes, countries with more similar cultures (using Hofstede's schema of cultural traits) tend to engage in greater information disclosure (particularly if they measure more highly on the 'individualism' trait: see Adair 2003).

Comparisons of intra-cultural practices indicate that 'collectivist' and 'individualist' cultures engage in contrasting practices on many aspects of negotiation: time-horizon of goals, direct/indirect information exchange, nature of opening offers etc. However, behavior in inter-cultural negotiations did not always mirror that of intracultural bargaining.

At the level of perception and cognition, some cultures (e.g. the United States) are distinguished by 'fixedpie' (or zero-sum) cognitive biases, while others are more likely to have a cooperative bias (e.g. Japan, China). Appropriateness of using ethically marginal tactics also varies considerably among cultures. ${ }^{1}$ One finding of great importance to the development of improved methods of inter-cultural negotiations is that across many cultures, use of ethically marginal tactics correlates strongly with perceived honesty and ethicality of the negotiating 'other' (Volkema et al. 2004).

\section{BARRIERS TO EFFECTIVE INTER-CULTURAL NEGOTIATIONS: CHINA AND U.S.}

One can infer from the research cited above that barriers to effective U.S.-China negotiations are especially high. Multiple factors, such as the contrasting individualist/collectivist traits and their effects on group dynamics, or contrasting cognitive biases (cooperative/fixed pie) would seem to assure difficulties. Chinese tend to be relativistic decision makers, who reject absolute moral philosophies and tend to be situationists (Redfern \& Crawford 2004). US students are more likely to exhibit idealistic concerns (e.g. concern for the environment and the welfare of others and avoiding harm to others) than their Chinese counterparts (Whitecomb et al. 1998). Chinese tend to rely less on idealistic concern and more on economic or self-interest driven concerns. Managers in North China tend to be more relativists than those in the South, managers in the South of China were significantly higher on idealism than managers in the North (Redfern and Crawford 2004).

Chinese negotiators view the win-loss negotiation strategy as immoral (Pitta et al. 1999). Competitive behaviors involve being determined, independent, individualistic, decisive and brave. Competitive behavior means standing up for one's own rights, defending a position, or simply trying to win, and consequently, competitive

\footnotetext{
${ }^{1}$ The 'ethically marginal' tactics researched include: (1.) Misrepresentation of position to an opponent. The negotiator distorts his/her preferred settlement point. (2.) Bluffing. The negotiator falsely states his/her intentions to perform some act. Bluffs can generally be described as false promises and false threats. (3.) Falsification. A third form of lying is the introduction of erroneous, incorrect information as though it were true. Examples include erroneous and misleading financial information, certifications of "proof", or false warranties and guarantees. Whether spoken or printed, falsification attempts to use erroneous information to change the opponent's position by distorting the facts themselves. (4.) Deception. Deception attempts to manipulate the opponent's logical and inferential processes, in order to lead the opponent to an incorrect conclusion or deduction. First, negotiators may only present part of the relevant information, and not "tell everything". (5.) Selective disclosure or misrepresentation to constituencies. This final form of lying occurs in situations where other parties - in addition to the opponent - are involved in the negotiating relationship. The primary difference is in the target audience. Negotiators may misrepresent the events which occur at the negotiating table to their constituencies, or may misrepresent the constituents' desires to the opposing negotiator. (See also, Lewicki et al. 2006).
} 
negotiators are more likely to pursue their own individual benefits. Competitive behaviors are not highly rewarded in traditional Chinese society, and sometimes people may get penalized for being competitive. As such, even though competitive behaviors could satisfy ones own needs, competing with the other side would damage the relationship, and in the long run, being competitive may not be worthwhile.

Chinese people usually try to avoid competitive behaviors in order to save their partners' face and maintain harmonious relationships with each other. However, if they believe that they possess information that could benefit others and a win-win solution is possible, they might be very proactive so as to push the other side to fully exchange information.

Members of collectivistic cultures perceive and manage conflict differently from those in individualistic cultures. Collectivistic societies tend to avoid open conflict, and when a conflict emerges, it must be resolved in inner circles before it becomes serious enough to justify public involvement. When successive efforts within the inner circle fail, the conflict is likely to be met with resolute force by the authorities (Ting-Toomey 2005). The collectivistic orientation that emphasizes harmony and minimizes disruption would likely motivate PRC executives to avoid potential conflicts or to smooth over issues.

Chinese negotiators have been observed to use delaying tactics (Hendryx 1986). Chinese use more obliging and conflict-avoiding resolution styles than do American subjects (Trubisky, Ting-Toomey and Lin 1991). PRC executives followed traditional Chinese values (e.g., concern for social relationships, etc.) in their decisions, while the Canadian executives showed more concern for goal achievement (Tse et al. 1994).

Group dynamics phenomena, such as 'groupthink', 'group polarization' and 'in-group preference' (e.g. Turner and Pratkanis 1998) present challenges to intra-cultural negotiations. These phenomena are likely to loom even larger in cultures with pronounced collectivist traits such as those in East Asia. At the root of many well known forms of group dysfunction is the tendency to engage in self-limiting behavior. A study by Heine, Takata, and Lehman (2000) found that in comparison with Canadian subjects tendency to engage in self-enhancement while in a group context, Japanese subjects in a similar context tend to self-criticize. Exaggerated claims of contributions to group efforts appear to be common among U.S. subjects, resulting in perhaps a lesser degree of group cohesion than is found in collectivist cultures. Yet the above-mentioned forms of group dysfunction still occur in the U.S. Additional research indicates that social loafing is less prevalent in the People's Republic of China than in the U.S. (Earley 1989). Thus, the evidence leads us to argue that group functionality and dysfunctionality are likely to be greater in China and other collectivist societies (the two phenomena are not orthogonal). Thus, group dynamics are likely to impede effective inter-cultural negotiations even more that they hinder intra-cultural negotiations. Groupthink and in-group biases are likely to lead to a Chinese negotiating team holding even more stereotyped views of their U.S. counterparts than they would have held before coming together as a group.

The operation of group dynamics in a Chinese context could lead to an intensification of inter-group conflict in the conduct of inter-cultural negotiations. The Chinese tradition provides frameworks beyond Confucianism as a guide to interpersonal behavior. Tjosvold et al (2004) attribute a 'strategic' tradition to Chinese negotiation which is an alternative to and at variance with Confucianism. In the strategic tradition the objective is to achieve defeat and humiliation of one's opponent, going beyond zero-sum bargaining as it is normatively presented in managerial literature. Zimbardo's (2007) seminal research has demonstrated that the capacity to treat the collective 'other' (whether prisoners, opposing armies, or negotiation teams) with greater harshness and cruelty is enhanced by the depersonalization and stereotyping of the other.

Group dysfunction is likely to be severe in collectivistic cultures. Intra-culturally, phenomena such as groupthink, group polarization, and common information effect are associated with many failures, and are characterized by creating distorted views of the 'other' (whether out-group members or competitors).

The above findings imply difficulties in achieving effective negotiations in variety of situations: distributive bargaining and inter-cultural group negotiations (whether integrative or distributive). Thus, the following propositions can be logically made: 
Proposition 1: U.S.-Chinese negotiations in distributive bargaining situations are likely to produce poor issue and relationship outcomes due to American's fixed pie mentality.

A key challenge in attaining positive negotiation outcomes between Chinese and American negotiators involves overcoming the fixed pie mentality prevalent in the U.S. There are relatively few purely distributive bargaining situations, therefore it is incumbent on Chinese negotiators need carefully define the bargaining situation in order make their American partners realize the integrative aspects of a given negotiation scenario. This may induce American negotiators to engage in more cooperative behaviors, although, as we argue below, it is imperative to screen for the fixed-pie mentality in the selection of personnel for a U.S. negotiation team.

Proposition 2a: Group dynamics in a collectivist culture are likely to lead to suboptimal information disclosure behavior in inter-cultural group negotiations.

Proposition 2b: Group dynamics in a collectivist culture are more likely to lead to the adoption of ethically marginal tactics in inter-cultural group negotiations.

For the Chinese negotiator, there is the lurking risk that highly competitive, even vengeful behavior may emerge if they perceive that face has been violated, an outcome that is all too possible they negotiate with persons from an individualistic background in which the members in the group are teamed based on mutual interests instead of group discipline.

\section{CONFUCIAN ETHICAL FRAMES AND CHINESE NEGOTIATION BEHAVIOR}

The notion of harmony between man and nature, between man and Heaven, and between man and man of Confucianism urges individuals to adapt to the collectivity, to control their own emotions, to avoid competition and conflicts, and to maintain harmony. There will be efforts to avoid antagonisms that unsettle the group or that place the individuals in direct confrontation. Therefore, the Chinese are more likely to avoid conflict, and when confronting conflicts, to seek harmony and to maintain collectivity in the process of negotiation, which is quite different from Western negotiation styles: direct, confrontational, competitive, and sometimes combative. While silence may be used as an effective negotiation the West, when it is employed by Chinese negotiators or even when they walk away from the negotiation tables, they may just be trying to avoid direct confrontations with their counterparts, while Westerners tend to interpret the behavior as some kind of trick they should try to avoid being trapped in (Ma 2006).

The display of negative emotions during negotiations can lead to a loss of face for Chinese. The frequency and intensity of emotions experienced was lower for Chinese. Emotional expression for Chinese might be considered dangerous, irrelevant, uncivilized, juvenile, or illness-causing (Lee,Yang and Graham 2006).

Confucian based negotiators may be more motivated to settle for a less than an optimally desirable agreement insofar as the emergence of the agreement helps the negotiators in achieving their face related goals (Kumar 1999: 309). Hong Kong Chinese favor compromise solutions more often than Americans. PRC negotiators were more likely to avoid conflict and to recommend discontinuing negotiations than Canadians (Tse et al. 1994). Collectivists tend to be more sensitive to emotions stemming from violations of relational norms than to emotions stemming from failure to attain desired goals (Luomala et al. 2004). The same emotional state can lead to different responses: that is, 'unjustifiably caused frustration' results in overt aggression for Americans, but not for Japanese (also a collectivistic culture). Chinese were more anxious, apprehensive, uncertain, quiet, frustrated, friendly, and angry at themselves; and the Dutch felt more irritated and Uljin et al. 2005 thus conclude: 'Collectivist cultures prefer conflict avoidance while more individualistic cultures rather are not afraid of direct conflict (Uljin et al. 2005: 107).

The Confucian negotiator is more likely to be reluctant to enter a contract, on the assumption that high moral virtue and strong relational bonds should render written agreements unnecessary. As Hamilton (1994: 198) explains: 
Whereas in the West laws regulate the actions of people, norms in Asia order the relations among roles. The Chinese emphasis on a hierarchy of ordered relationships and on harmony among those relationships formed a powerful worldview for creating social, political and economic institutions... The crucial in the Chinese setting is not the Western question of who had jurisdictional control over the economy or economic institutions. Instead, the crucial issue for China was how the world, including the economy, should be harmoniously arranged, and how could people's livelihood be guaranteed. For the Chinese, in principle, everyone always had a part to play in creating and maintaining economic harmony.

Thus, China developed an alternative system to that of law and contracts for creating social and economic order. Elaborate written contracts and aggressive, classical contracting are thus normatively distasteful to Confucian ethical sensibilities. Added to this, the high priority of preserving 'face' in relationships leads to difficulties in effectively attaining to pure forms of distributive and integrative bargaining outcomes.

Proposition 3a: Norms and values regarding relational bonds would inhibit Confucian negotiators from engaging in classical, 'arms-length' contracting.

Proposition 3b: Norms and values regarding relational bonds would inhibit Confucian negotiators from reaching optimal integrative-bargaining outcomes, as they would prefer relative parity of outcomes to more optimal, though unequal outcomes.

The implications of the above propositions are that the Chinese negotiators need to be more adaptive to the negotiator partner's cultural background and develop adaptive negotiation framework instead of insisting on the primacy of their own cultural imperatives. The need for selecting high CQ individuals for negotiation teams applies equally to Chinese and U.S. sides of the bargain.

\section{FRAMEWORK FOR IMPROVING U.S.-CHINESE NEGOTIATIONS}

A basic tenet of effective negotiation practice is a contingency approach, acknowledging that different practices are best suited to different negotiation situations. Thus, a different methodology would be appropriate for the improvement of distributive bargaining and integrative bargaining. Additional modifications would be required to deal with factors introduced when the relevant bargaining units are groups, as opposed to individuals.

A potentially valuable contribution towards developing improved methods for Chinese-U.S. negotiations in integrative situations lies in an 'ethical framing' approach. Confucian philosophy speaks persuasively for the ethic of relationships, cooperation and harmony. The normative negotiation literature (see Lewicki et al. 2006) stresses the importance of discussions about values and negotiation philosophy in laying the foundations for information disclosure and iterative trust-building. Negotiations encompass bargaining over process as well as content; though process is frequently not explicitly discussed, permitting implicit misunderstanding to take root. Negotiating process is an opportune phase in which to raise issues of philosophy, values and norms. It is also an ideal phase in which to invest in confirming face of the opposing negotiating team. Tjosvold et al (2004) have found that Chinese, in an intra-organizational context, can openly discuss areas of disagreement with a consequent enhancement of relationships, so long as face is carefully confirmed at the outset of discussion. However, such interactions are likely to prove much more difficult in a U.S.-China negotiation context.

We argue that the capacity of U.S. negotiators to address their Chinese counterparts by correctly utilizing Confucian ethical frames has the potential to improve processes as well as, issue and relationship outcomes for integrative bargaining situations. The empirical findings of Volkema et al. (2004) support our contention. These researchers discovered that a negotiator's perception of his opponent/partner's ethical disposition was the best predictor of the use of ethically marginal tactics, whereas, a subject's attitudes towards marginal tactics was not a significant predictor of the use of those tactics. Thus, a critical obstacle for the U.S. negotiator is to convince his Chinese partners of his goodwill, good intent and benign ethical disposition during the process negotiation phase. We do not hold that all ethical systems are culturally relative; rather there are plural ethical systems in the world, several of which make claims to universality. Confucian is one of these grand systems of ethics with universal claims. Thus it is vital for U.S. negotiators to understand the language of Confucianism, especially with regard to relational norms and values, and to be prepared to invest heavily in the negotiation of process, especially devoting 
much longer periods of time to the initial phases than are normal for U.S. negotiators.

Proposition 4a: The effective use of Confucian ethical frames in early stages of integrative bargaining is likely to result in increased information disclosure between negotiation partners from the U.S. and China.

Proposition 4b: The effective use of Confucian ethical frames in early stages of integrative bargaining is likely to result in decreased use of marginal ethical tactics between negotiation partners from the U.S. and China.

Proposition 4c: The effective use of Confucian ethical frames in early stages of integrative bargaining is likely to result in improved issue and relationship outcomes in inter-cultural negotiations.

Factors that are likely to moderate the effects of Confucian ethical frames include dispositional variables such as cultural intelligence and moral maturity (e.g. Earley and Peterson 2004; Kohlberg and Ryncarz 1990), cognitive biases such as the 'fixed-pie fallacy', as well as, group dynamics such as group polarization. CQ levels are likely to correlate positively with a Confucian framing approach, with high-CQ agents more likely to deploy the framing convincingly and in ways that resonate with the Chinese negotiation partners. Those at pre-conventional levels of moral maturity are less likely to follow through with the consistent ethical behavior required to slowly build trust, regarding the Confucian ethical frames as opportunistic influence tactics. Also, those agents having a fixed-pie cognitive bias are also less likely to deploy the strategy effectively, as it goes against deeply ingrained belief systems. Thus, selection of U.S. agents for negotiation with Chinese is a critical policy issue. Psychometric assessment should screen out individuals having low CQ and fixed-pie mentalities, for example. Additionally, it is critical for U.S. agents to learn the logic and rhetoric of Confucian ethics.

Proposition 5a: Negotiators with a zero-sum or 'fixed-pie' mentality are unlikely to be effective in credibly conveying Confucian ethical frames during process negotiations and will tend to discourage information disclosure between negotiation partners from the U.S. and China.

Proposition 5b: Confronted with a negotiator with a zero-sum bargaining mentality, the ineffective usages of Confucian ethical frames tend to increase the usage of marginal ethical tactics between negotiation partners from the U.S. and China.

Proposition 5c: Confronted with a negotiator with a zero-sum bargaining mentality, the ineffective usages of Confucian ethical frames tend to damage the relationship outcomes in inter-cultural negotiations.

The obverse of Confucian ethical framing is the use of 'competitive frames' for effectively conducting zero-sum bargaining. As stated above, Chinese negotiators are at a disadvantage in reaching optimal outcomes in zero-sum games. These are likely to result in damaged relationships, and possibly, the escalation of rivalry and counterproductive conflict. Inter-cultural dynamics may even result in reactive, overly aggressive (and therefore destructive) behavior on the part of Chinese negotiators. However, it may be essential for Chinese negotiators to sometimes engage in distributive bargaining. One means of facilitating this is the specialized training in zero-sum bargaining among a cadre of specialist, professional negotiators.

The obstacles to effective U.S.-China negotiation processes and outcomes are many. The improvement of practice is a policy science, which is said to be experimental, a result of applied trial and error learning, rather than the domain of grand theorizing. In this paper we have provided some practical conceptual building blocks, upon which improved negotiation practices between U.S. and Chinese partners may be crafted.

\section{AUTHOR INFORMATION}

Rashmi Prasad (PhD University of Kentucky) is Professor of Business Administration at the University of Alaska Anchorage. His principal research interests are in the areas of Cross-Cultural Management Issues, Business Ethics, and Health Systems Administration. He has published articles in numerous journals, including Governance and The Journal of Business Ethics, as well as contributing chapters to several books. E-mail: Afrp2@cbpp.uaa.alaska.edu 
Yong Cao (Ph.D., University of Iowa) is Associate Professor of Marketing at the University of Alaska Anchorage. He has published papers in leading journals, such as Journal of Marketing, Journal of Retailing, Journal of Consumer Behavior, Journal of Interactive Marketing, Journal of Service Research, International Journal of Electronic Commerce. His research interests and expertise are Pricing, E-commerce, Banking, Marketing Models, Customer Relationship Management and International Marketing and Management. E-mail: afyc @uaa.alaska.edu. Corresponding author.

\section{REFERENCES}

1. Adair, W. 2003. Integrative Sequences and Outcome in Same-and Mixed-Culture Negotiations. International Journal of Conflict Management, 14:314: 273-296.

2. Brett, J.M., and Okumura, T. 1998. Inter- and Intracultural Negotiations: U.S. and Japanese Negotiators. Academy of Management Journal, 41: 495-510

3. Earley, P. 1989. Social Loafing and Collectivism: A Comparison of the United States and the People's Republic of China. Administrative Science Quarterly, 34: 565-581.

4. Earley, P. and Petersen, R. 2004. The Elusive Cultural Chameleon: Cultural Intelligence as a New Approach to Intercultural Training for the Global Manager. Academy of Management Learning and Education, 3(1): 100-115.

5. Foster, D. 1992. Bargaining Across Borders: How to Negotiate Business Successfully Anywhere in the World. New York: McGraw-Hill.

6. Graham, J.L. 1993. The Japanese Negotiation Style: Characteristics of a Distinct Approach. Negotiation Journal, 9: 123-140.

7. Heine, S., Takata, T. \& Lehman, D. 2000. Beyond Self-Presentation: Evidence for Self-Criticism among Japanese. Personality and Social Psychology Bulletin, 26( 1): 71-78.

8. Hendryx, S. 1986. Transfer Joint-Venture in the People's Republic of China: A Management Perspective. Columbia Journal of World Business.

9. Kohlberg, L. and Ryncarz, R. 1990. Beyond Justice Reasoning: Moral Development and the Consideration of a Seventh Stage. In Charles Alexander and Ellen Langer (Eds.), Higher Stages of Human Development. New York: Oxford University Press.

10. Kumar, R. 1999. A Script Theoretical Analysis of International Negotiating Behavior, in Bies, Lewicki, and Sheppard (eds.) Research in Negotiation in Organizations, Vol. 7, Stamford, CT: JAI Press, pg. 285311.

11. Lee, K., Yang, G., \& Graham, J. 2006. Tension and Trust in International Business Negotiations: American Executives Negotiating with Chinese Executives. Journal of International Business Studies, 37(5): 623635.

12. Lewicki, R.J., Saunders, D.,M., \& Barry, B. 2006. Negotiation (3rd Ed). McGraw- Hill International Edition.

13. Luomala, H.; Kumar, R.; Singh, J.; Worm, V.(2004)., "Cross cultural differences in mood regulation: A comparison of individualistic and collectivistic societies", Journal of International Consumer Marketing, Vol.V16, Issue 4, 39-62.

14. Ma, Z. 2006. "Negotiating Into China: The Impact of Individual Perception on Chinese Negotiation Styles". International Journal of Emerging Markets, 1(1): 64-71.

15. Pitta, D, Fung, H., \& Isberg, S. 1999. Ethical Issues Across Cultures: Managing the Differing Perspectives of China and the USA. Journal of Consumer Marketing, 16(3): 240-256.

16. Redfern, K. \& Crawford, J. 2004. An Empirical Investigation of the Influence of Modernisation on the Moral Judgments of Managers in the People's Republic of China. Cross Cultural Management: An International Journal, 11:1: 48-61.

17. Tjosvold, D, Hui, C., and Sun, H. 2004. Can Chinese Discuss Conflicts Openly? Field and Experimental Studies of Face Dynamics in China. Group Decision and Negotiation, 13: 351-373.

18. Ting-Toomey, S. 2005. The Matrix of Face: An Updated Face-Negotiation Theory. In Theorizing about Intercultural Communication, W. Gudykunst, ed., Sage Publications.

19. Trubisky, P., Ting-Toomey, S, \& Lin, S. 1991. The Influence of Individualism-Collectivism and SelfMonitoring on Conflict Styles. International Journal of Intercultural Relations, 15(1): 65-84. 
20. Tse, D., Francis, J. \& Walls, J. 1994. Cross-Cultural Differences in Conducting Intra- and Inter-Cultural Negotiations: A Sino-Canadian Comparison. Journal of International Business Studies, 23: 537-555.

21. Turner, M, and Pratkanis, A. 1998. Twenty-Five Years of Groupthink Research: Lessons from the Evolution of a Theory. Organizational Behavior and Human Decision Processes, 73: 105-115.

22. Uljin, J., Rutkowski, A., Kumar, R. \& Zhu, Y. 2005. Patterns of Feeling in Face-To-Face Negotiations: A Sino-Dutch Pilot Study. Cross Cultural Management, 12(3): 103-118.

23. Volkema, R., Fleck, D. \& Hofmeister-Roth, A. 2004. Ethicality in Negotiation: An Analysis of Attitudes, Intentions and Outcomes. International Negotiation, 9: 315-339.

24. Whitecomb, L, Erdener, C and Li, C. 1998. Business Ethical Values in China and the U.S. Journal of Business Ethics, 17(8): 839-852.

25. Zimbardo, P. 2007. The Lucifer Effect: Understanding How Good People Turn Evil. New York: Random House.

\section{NOTES}

